\title{
Experiences with pregnancy among female sex workers in Ethiopia: A Link Up exploratory study
}

Population Council

Miz-Hasab Research Center

Organization for Social Services for AIDS

Follow this and additional works at: https://knowledgecommons.popcouncil.org/departments_sbsr-hiv

Part of the Demography, Population, and Ecology Commons, Family, Life Course, and Society Commons, International Public Health Commons, and the Women's Health Commons How does access to this work benefit you? Let us know!

\section{Recommended Citation}

Population Council, Miz-Hasab Research Center, and Organization for Social Services for AIDS. 2015. "Experiences with pregnancy among female sex workers in Ethiopia: A Link Up exploratory study," Study brief. Washington, DC: Population Council. 


\section{EXPERIENCES WITH PREGNANCY AMONG FEMALE SEX WORKERS IN ETHIOPIA: A LINK UP EXPLORATORY STUDY}

In Ethiopia, it is illegal to operate a brothel or procure sex workers as a commercial activity, but the sale of sex by women is not prohibited by law. ${ }^{1}$ Research suggests that the number of Ethiopian female sex workers is growing, with younger women and girls increasingly entering the sex trade. Public health programs and policies typically have emphasized HIV prevention in this vulnerable population. ${ }^{2}$ A 2014 study of 3,882 Ethiopian female sex workers found that HIV prevalence in the 10 study sites ranged from 15 percent to 33 percent, compared to national prevalence of 1.9 percent among women. ${ }^{3,4}$

Furthermore, since most female sex workers are of reproductive age, female sex workers wishing to delay or limit childbearing are at heightened risk of unintended pregnancy. ${ }^{5}$ Available data suggest that unprotected sex and pregnancy are common among Ethiopian female sex workers. In the 2014 survey, about half of female sex workers had given birth, and 13.7 percent had terminated a pregnancy. ${ }^{3}$ In a separate study of Adama City female sex workers, women reported inconsistent condom use, particularly with non-paying sexual partners such as boyfriends or husbands. ${ }^{6}$

Although survey data shed light on the high prevalence of pregnancy among female sex workers, little is known about the contexts in which they get pregnant and have children. For example, there is much to be learned about whether and how they continued working during their pregnancies; their relationships with their children's fathers; or whether they access antenatal care and prevention of mother-to-child transmission (PMTCT) services. We know of no existing studies that describe the outcomes of Ethiopian female sex workers' pregnancies or the maternal health services obtained. An exploration of female sex workers' reproductive history in Ethiopia will provide important information to inform the development of programs and policies that promote

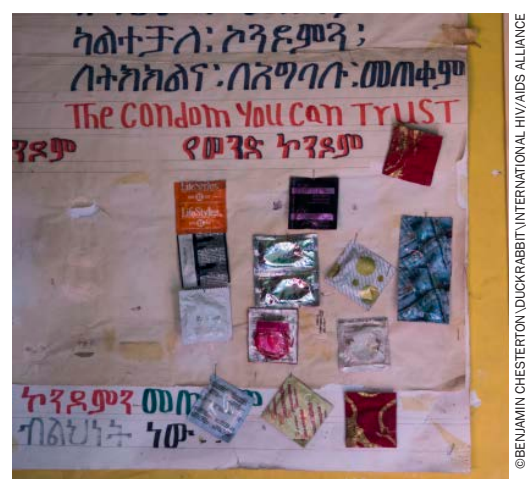

Consistent condom use should be promoted with all sexual partners.

\section{KEY MESSAGES}

Consistent condom use-either alone or combined with other effective contraception-should be promoted with both paying and non-paying sexual partners.

Pregnant sex workers often continue to sell sex late into their pregnancies, underscoring their need for maternal health care and prevention of mother-to-child transmission services.

In addition to emphasizing HIV and STI prevention and care, programs should ensure that female sex workers have access to essential reproductive health services such as pregnancy testing, emergency contraceptive pills, antenatal care, safe delivery, postnatal and postpartum care, and safe abortion services.

Female sex workers experience violence by a range of perpetrators. This demands a comprehensive and multisectoral response, including sensitization of law enforcement officials; peer-led mobilization to prevent and respond to such abuse; and psychosocial services for women who experience violence.

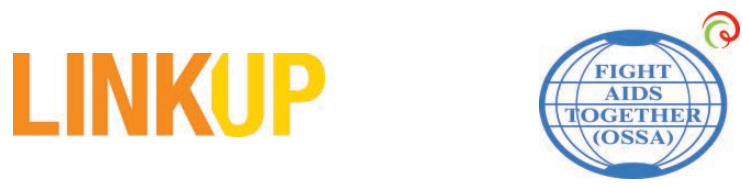

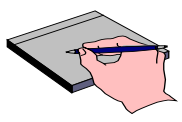

The Miz-Hasab Research Center Addis Ababa, Ethiopia
POPULATION COUNCIL

Ideas. Evidence. Impact. 
the comprehensive health and well-being of female sex workers.

Under the Link Up project, a global consortium led by the International HIV/AIDS Alliance, the Population Council, in collaboration with Miz Hasab Research Center and local Link Up implementing partner, Organization for Social Services for AIDS (OSSA), conducted a qualitative study to explore Ethiopian female sex workers' reproductive health histories as well as their experiences with pregnancy, childbearing, and motherhood.

\section{STUDY METHODOLOGY}

In September and October 2014, trained interviewers conducted hour-long in-depth interviews with 30 female sex workers who were receiving services at the OSSA office in Adama City; and 10 key informants who had experience with or expertise on the sexual and reproductive health needs of Adama female sex workers. The key informants included nongovernmental organization (NGO) staff, local health officials, and peer educators. Eligible female sex workers were aged 18 years and older and had ever been pregnant. The digitally recorded interviews covered the circumstances under which female sex workers have become pregnant; pregnancy outcomes; and maternal health behaviors. Interviews were conducted in Amharic, transcribed and translated into English, and analyzed by three researchers. This brief presents preliminary analysis of themes related to Adama City female sex workers' experiences with pregnancy and childbearing.

\section{STUDY POPULATION}

The 30 female sex worker participants were between the ages of 18 and 35 years, and they had completed between four and 10 years of education. Twenty-four had at least one living child, and 13 had a current intimate partner. Participants reported having been pregnant between one and five times. Fourteen women had terminated a pregnancy, and three of those women had had three or more abortions. Participants reported hotels, liquor houses, and the street as their primary places of sex work employment. Seventeen female sex workers were from Adama City, and the rest had migrated from other cities in the country.

The key informant participants consisted of three peer educators; five NGO staffers; and three local health officials.

\section{KEY FINDINGS}

\section{Use of condoms and non-barrier modern contraception}

All participants stated that they used condoms, but with variable consistency. A recurring theme was that female sex workers were very diligent about using condoms with paying clients, but did not use condoms with intimate partners (often referred to as balukas). Although nearly all said that they felt confident in their ability to insist on condom use with clients, many feared the negative reaction they would receive from intimate partners if they were to ask that they use condoms. Women often mentioned love as another reason for not using condoms with intimate partners.

So, if I do not use condoms one day and ask [my lover] to use another day, he may think something else. He may quarrel with me. We may separate. And, since I love him, I do not want that. Once we do not use condoms, we stick to it. We all do this.

-Sex worker, age 29

Since he loves me and I love him, we do not think about condoms.

-Sex worker, age 25

They ask us for short-term birth control method, but we advised them to use condoms all the time with any of their clients as well as their balukas. However, they go without condom with their balukas. For that, they worry about unexpected pregnancy.

$$
\text { -Key informant, NGO staffer }
$$


Both key informant and sex worker participants voiced a strong opinion that women currently selling sex work did not wish to have children; pregnancies among female sex workers are virtually always unintended. Frequently mentioned reasons participants gave for wishing to avoid pregnancy included: fear of giving birth to a child without knowing the father's identity; concerns about whether they could continue to work while pregnant; and unwillingness to raise a child while selling sex. When asked whether female sex workers worry about pregnancy, one key informant responded:

Yes. Where can we deliver? We live in bars. There are different questions that come to sex worker's mind. For instance, the child may ask for his/her father. In addition, business will get decreased if a sex worker becomes pregnant. For that, sex workers don't want to get pregnant at all.

-Key informant, peer educator

In addition to condoms, 22 sex workers were currently using a non-barrier modern contraceptive method (i.e., injectable, pill, or implant). These women clearly articulated their rationales for using two methods, often explaining their decisions in terms of the need to prevent pregnancy with intimate partners while also protecting themselves from disease transmission with clients. Another common reason was to have back-up protection against pregnancy in the event of condom failure or forced sex.

I use condoms for making business, whereas the implant is to protect pregnancy since I go without condom with my boyfriend.

-Sex worker, age 26

Condoms may break. Some people may rape me without a condom. I do not want to get pregnant here. I have to protect myself.

-Sex worker, age 20
The injectable and implant were popular nonbarrier modern methods among contraceptive users, who felt that using these methods was more convenient than having to remember to take a daily pill. Some also mentioned that they liked that they did not menstruate when using these contraceptive methods; their work was not interrupted by their periods each month. The most commonly cited sources of information about family planning were local NGO programs and peer educators.

Among the eight women who were not currently using a non-barrier method, common reasons included their beliefs that they were at low risk of pregnancy; that it was not convenient to obtain the methods; that they did not like the side effects; or that they were not comfortable with the idea of using them.

\section{I became very fat due to the birth control method that I took. I was advised by a physi- cian to stop taking injection since it can be a cause for [high] blood pressure.}

-Sex worker, age 30

Of course, I didn't try any of the contraceptives; they are disgusting like the implant.

-Sex worker, age 19

\section{Emergency contraceptive pills}

Most participants had heard of emergency contraceptive pills (brand name Postpill), and they felt that they knew where to obtain them if needed (e.g., pharmacies, NGOs, family planning clinics). Some stated that the method was available free of charge in clinics, while others mentioned paying between 2 and 47 birr in pharmacies (between US\$.10 and \$2.32). ${ }^{*}$

However, participants' knowledge of this postcoital method's effectiveness was not always accurate. One woman mentioned that emergency contraceptive pills were only effective within the first three

\footnotetext{
*US\$1.00 $=20.28$ ETB as of February 2015.
} 
hours after unprotected sex, but most believed that they needed to be taken within 24 or 72 hours.

[T]here is a pill that should be taken within 24 hours after unprotected sex. I have never seen or used it but I heard it's like a pill and women used it when they go without protection. A majority of the sex workers have boyfriends and they don't use condoms, instead they use Postpill after intercourse.

-Sex worker, age 26

Six women reported that they had ever used emergency contraceptive pills. Their reasons for using them included condom breakage, lack of contraceptive use, and forced sex.

When I met my current lover, I stopped taking the injections. One day we had sex without condoms. We had taken some drinks and we were in the mood. I knew it was the time I could get pregnant. Then I went to Marie Stopes, which is nearby to where I live. The sister counseled me and gave me Postpill.

-Sex worker, age 26

Yes, one day a guy forced me to have sex without protection. I didn't want to get pregnant. I had to take Postpill, so I took it.

-Sex worker, age 24

\section{Current pregnancies}

Three of the 30 women were pregnant at the time of the interview, all unintended pregnancies. One had gotten pregnant by a client, one by a boyfriend, and one by an ex-boyfriend. Two of the three had had unprotected sex, but one reported that she had been on the pill and was unaware of how she could have gotten pregnant.

It was unintended. I was taking medicine [pills] and I didn't know I was pregnant until I was four months pregnant.

-Sex worker, age 25
But this [father] is my client; he told me that he would support me. I don't know what will happen.

-Sex worker, age 28

\section{Sex work while pregnant}

Eighteen of the 30 participants reported that they had continued sex work while pregnant, with several describing having sex with clients into their seventh or eighth month of pregnancy. They described varied reactions by clients, some of whom expressed a preference for pregnant sex workers.

Some [clients] did not care. Some would feel sorry for you, give you some money and walk away. Some ask you why you are doing this while pregnant.

-Sex worker, age 26

I was very anxious. I did not want [clients] to press me hard. Some clients understand my feelings, but some others don't.

-Sex worker, age 20

When our uterus is big, many [clients] leave the non-pregnant sex workers and come to us.

-Sex worker, age 23

\section{Maternal health care utilization}

Most of the participants said that they had received at least some antenatal care during their pregnancies, including HIV testing. They were familiar with where they could access maternal health services, and their primary motivations for seeking antenatal care and PMTCT services was out of concern for the welfare of their children. Although those who received antenatal care typically delivered in facilities, some delivered at home with unskilled attendants such as relatives or neighbors. 
I found out when I was three months pregnant. I went to the hospital and they told me that I was pregnant and I had follow ups for the rest of the time and I also got checked for HIV. But, I gave birth at home.

-Sex worker, age 22

During my first delivery, my labor was painful and stayed for about a week. However, during my second delivery, even I had no time to go to health facility so I delivered at home with my aunt's assistance.

-Sex worker, age 24

\section{Abortion experience}

Fourteen women had terminated at least one pregnancy. The abortion methods used included surgical and medication abortions in facilities, frequently mentioning Marie Stopes International clinics. Among those who obtained surgical or medication abortions in facilities, they expressed satisfaction with the experience. They reported paying fees ranging from 100 to 1,000 birr (roughly US\$5 to $\$ 50)$.*

They gave me a tablet. I took the tablet and I was told to come back after three days. When I came back the third day, they inserted a tablet into my womb. I didn't feel any pain.

-Sex worker, age 19

The reason for abortion is that sex workers do not know who the father is. Apart from this, they cannot perform their job being pregnant. Therefore, when sex workers want to abort their pregnancies, there is Marie Stopes in our town to offer such services. We make Marie Stopes our partner. For that, we send sex workers to get abortion service. There are some sex workers who do not know where to go for the same, so we inform them where to go for abortion.

-Key informant, NGO staffer
Some women also attempted to abort using traditional methods suggested by friends. Two women mentioned attempting to terminate a pregnancy by taking "ampicillin tablets with Coca Cola." In one case, the participant, aged 35 years, related how she had paid someone in her village who could "abort it for you traditionally; it almost killed me." This same woman ended up requiring postabortion care at a hospital. A similar story was told by a 22-year-old participant:

Somebody took me to this lady and I lied and told her that I was only four months pregnant.... But the procedure was really painful and it took days after days and she gave me glucose for days and sent me home. I was about to die and friends contributed money and sent me to Marie Stopes and they thought I was going to die but I survived.

\section{Female sex workers living with HIV}

Four of the participants were living with HIV. One had gotten pregnant since the time of the positive diagnosis, and her child has been diagnosed with HIV. She felt that vertical transmission could have been prevented had she been more knowledgeable about available PMTCT services.

One of my children is now 9 years old and she lives with the virus. This is because I gave birth at home and breastfed her without knowing anything.

-Sex worker, age 35

Three of the four women living with HIV were on antiretroviral therapy (ART). The one who was not on medication stated that she found ART to be too inconvenient, so she had discontinued use. The three ART users did not mention difficulties with treatment adherence, but one declared that she did not use non-barrier contraception because she believed that ART should not be combined with any other medication. 
I take ART. Taking another medicine will

bring me harm. My body has adopted the

medicine. I went to see a doctor and I don't

use other medicines.

-Sex worker, age 30

All four women said that they used condoms consistently with clients; they expressed a strong sense of obligation to protect the health of their clients. One reported that she used two condoms at a time as an extra precaution, insisting that this is effective as long as the condoms are applied correctly. Another woman spoke about clients trying to have unprotected sex despite their awareness of her positive status.

Some of them will tell me that since have started taking ART, there is no problem. But the virus I have and the virus in the other person are different, so using condoms is a must.

-Sex worker, age 35

Despite their diligence about using condoms with clients, some felt that they could not use condoms with their boyfriends; these intimate partners often refused to use condoms.

[My boyfriend] knows that I am HIV positive. I told him but he didn't care, so I thought he is also HIV positive.

-Sex worker, age 35

\section{Motherhood and sex work}

The circumstances under which participants became mothers varied, but a commonly expressed sentiment was the challenge of working as a female sex worker with children. They mentioned their struggles with finding child care, with many opting to pay neighbors or landlords to watch their children. Others reported that their children live with relatives. They frequently mentioned their concerns about their children discovering what their mothers did for a living, particularly in cases when they see clients in their homes.
[My daughter] doesn't ask me what I am doing. She thinks I am selling tella (local drink). But she asks me where I am going. I even tell the lady who takes care of my children that I work at a factory at night.

-Sex worker, age 23

My younger daughter was so smart; so she asked me how I am getting money. She said, 'Mommy your clothes are clean because you didn't perform any household chores, so how did you get the money? From where did you bring us money?' I told her I cleaned rooms at the hotel and I get paid for that.

-Sex worker, age 35

A universal theme among sex workers who are mothers was a strong sense of commitment to providing for their children, despite their unhappiness working in the sex trade. When asked about their desire to quit sex work, many framed their exit strategy in terms of the welfare of their children. On one hand, they did not want to quit until they had another way of earning money to support their children. On the other hand, they felt an urgency to get out of sex work in order to shield their children from the negative aspects of their jobs.

My son will start primary school after three years, so I don't want to see my son be insulted at school due to my work. I was among the best students. I dropped out from school due to my pregnancy. Besides, I raised my son being tested by different challenges. So, I don't want to see my son being unhappy. For that, I will surely quit sex work.

-Sex worker, age 20

I will quit sex work for the sake of my child's life. I started sex work since I had no option. But now I have fulfilled the needs of my son and I have saved 20 to 30 birr per day in the form of iqub (traditional savings mechanism). ...I want to quit sex work soon.

-Sex worker, age 30 


\section{Experiences of violence}

Several women described experiences of violence at the hands of lovers, clients, and law enforcement officers. The reported incidents included beatings, rape, and verbal abuse. In some cases, women were beaten when trying to insist that a client or boyfriend use a condom. Physical and verbal abuse were accompanied by theft in some cases, with men either stealing from the women or refusing to pay after sex.

I thought he would carry condoms. At the time, I was too ashamed to ask men if they had condoms. I didn't know such things then. When it was clear he wanted to have sex without condoms, we started struggling. Then I cried for help, when he started hitting me.

-Sex worker, age 25

There are plenty of such events here. Not so much by our clients but it is the police who harass us a lot on the streets. They ask us to give them money. They take all what we have done during the night. All sex workers are condemned as thieves if there is one sex worker who steals something. Sometimes there is gang raping and nothing is done about it.

-Sex worker, age 23

\section{PROGRAM IMPLICATIONS AND RECOMMENDATIONS}

Study participants recruited at the site of Link Up partner OSSA had access to sex worker-friendly services, and it was evident that they were aware of and had access to critical sexual and reproductive health education and care. Use of condoms and non-barrier modern contraception was common among participants, but many also had experienced unintended pregnancy and abortion. Despite high levels of recognition of the negative consequences of unprotected sex, the most common reasons for unintended pregnancy were inconsistent or nonexistent contraceptive use-condoms or otherwise. This risky behavior was particularly pronounced with intimate partners. While it is encouraging that participants exhibited high levels of knowledge about HIV prevention and family planning, this knowledge did not always translate into consistent, correct method use.

Most women had heard of emergency contraceptive pills, but none were aware of current guidance that the method could be effective up to 120 hours after unprotected sex, rather than the frequently cited effectiveness window of 72 hours. ${ }^{7}$ Peer educators and health care providers should make efforts to update this guidance. In cases where pregnant sex workers elect to terminate their pregnancies, program staff and health care providers should ensure that these women receive information on where they can obtain safe abortion care.

Violence is a pervasive problem among sex workers, often a manifestation of the stigma and gender inequity that these women face as a marginalized community. Many women expressed a sentiment of helplessness and resentment towards law enforcement officials who did not offer them protection or assistance. The range of perpetrators mentioned included intimate partners, clients, and police men, many of whom may not typically be reached by HIV prevention programming for sex workers. To prevent and address violence among female sex workers, a comprehensive multisectoral response is necessary that could include peer mobilization, psychosocial counseling, and sensitization of police officers.

Although the common sentiment expressed in this exploratory study was that female sex workers did not wish to become pregnant while selling sex, previous studies among indicate that the desire to prevent pregnancy is not universal among female sex workers. In either case, health care providers and programs that serve these women should respect their individual rights and desires regarding childbearing, recognizing that both childbearing and pregnancy prevention are legitimate choices. 
Programs that serve these women should make concerted efforts to ensure access to pregnancy testing, antenatal care and PMTCT, safe conception counseling, and safe delivery services.

Reproductive health and maternal health content should be integrated into HIV prevention programming for female sex workers, with an emphasis on recognizing and upholding their SRHR. Programs such as OSSA's represent a promising platform on which to build comprehensive sexual and reproductive health offerings for Adama City female sex workers.

\section{REFERENCES}

${ }^{1}$ Article 634: The Criminal Code of the Federal Democratic Republic of Ethiopia (Proclamation No. 414/2004) 2004.

${ }^{2}$ Overs, C. et al. 2011. "Sex work in Ethiopia: Mapping the impact of law, policy and enforcement practices." Paulo Longo Research Initiative. Michael Kirby Centre for Public Health and Human Rights, Monash University.
${ }^{3}$ Ethiopian Public Health Institute, Ethiopian Public Health Association, Centers for Disease Control and Prevention, Federal HIV/AIDS Prevention and Control Office. 2014. Ethiopian National Key Population HIV Sero-behavioral surveillance (NHSBS) Round 1 Progress Report. Addis Ababa.

${ }^{4}$ Central Statistical Agency [Ethiopia] and ICF International. 2012. Ethiopia Demographic and Health Survey 2011. Addis Ababa, Ethiopia and Calverton, Maryland, USA: Central Statistical Agency and ICF International.

${ }^{5}$ Wilcher, R., W. Cates, Jr, and S. Gregson. 2009. "Family planning and HIV: strange bedfellows no longer," AIDS 23(Suppl 1): S1-6.

${ }^{6}$ Mooney, A. et al. 2013. "Work-related violence and inconsistent condom use with non-paying partners among female sex workers in Adama City, Ethiopia," BMC Public Health 13: 771.

${ }^{7}$ World Health Organization. 2012. Emergency contraception: fact sheet no. 244. Available at: http:// www.who.int/mediacentre/factsheets/fs244/en/.

Link Up aims to improve the sexual and reproductive health and rights (SRHR) of one million young people affected by HIV across five countries in Africa and Asia. The project is being implemented by a consortium of partners led by the International HIV/AIDS Alliance.

Link Up consortium partners

- ATHENA Network

- Global Youth Coalition on HIV/AIDS

- International HIV/AIDS Alliance

- Marie Stopes International in Bangladesh, Myanmar and Uganda

- Population Council

Other key collaborators include UNFPA, UNESCO and AIDS Fonds. Funded by the Ministry of Foreign Affairs of the government of the Netherlands (BUZA).

To follow the progress of Link Up, visit www.link-up.org
- STOP AIDS NOW!

- Alliance Burundaise Contre le SIDA in Burundi

- Organisation for Support Services for AIDS (OSSA) in Ethiopia

- Alliance Myanmar

- Community Health Alliance Uganda
POPULATION COUNCIL

Ideas. Evidence. Impact.
The Population Council confronts critical health and development issues-from stopping the spread of HIV to improving reproductive health and ensuring that young people lead full and productive lives. Through biomedical, social science and public health research in about 50 countries, the Council works with our partners to deliver solutions that lead to more effective policies, programs, and technologies to improve lives worldwide. Established in 1952 and headquartered in New York, the Council is a nongovernmental, nonprofit organization with an international board of trustees.

Suggested citation: Population Council, Miz-Hasab Research Center, and Organization for Social Services for AIDS. 2015. "Experiences with pregnancy among female sex workers in Ethiopia: A Link Up exploratory study," Link Up Study Brief. Washington, DC: Population Council. 